\title{
¿PUEDE SER LA RADIO UNA HERRAMIENTA PEDAGÓGICA PARA LA SANA CONVIVENCIA?
}

\author{
Gloria Elena Arenas García ${ }^{91}$
}

\begin{abstract}
RESUMEN
El tema es enfocado desde el valor de un medio de comunicación, como herramienta para las comunidades que han sido vulneradas en sus derechos, como integrantes de comunidades organizadas y que hoy trabajan en la construcción de espacios de convivencia, respeto y tolerancia, promoviendo su quehacer a través de la magia de la radio. ¿Consideran, amigos lectores, que la radio puede ser un canal por el cual se pueden materializar propuestas educativas y pedagógicas que lleven al fortalecimiento de la convivencia, la tolerancia y el respeto en las comunidades? Los humanistas y oportunistas están convencidos que hoy no puede consolidarse ningún liderazgo sin la mediación de los medios.
\end{abstract}

Los medios, especialmente los audiovisuales, han alcanzado en menos de un siglo una preponderancia como no tuvo ningún emperador en la historia, como no acumuló ninguna otra institución en tan corto tiempo. La radio y la televisión, ambas, seducen multitudes. La radio y la televisión no son hermanas enemigas a las dos les sobran pretendientes.

Palabras clave: pedagogía, educación, derechos humanos, la radio.

\begin{abstract}
The subject will be focused from the value of mass media, like tool for the communities that have been harmed in their rights, like members of organized communities and that today work in the construction of spaces of coexistence, respect and tolerance, promoting its task through the magic of the radio. Do you consider reading friends who the radio can be a channel by which can materialize educative and pedagogical proposals that entail to the fortification of the coexistence, the tolerance and respect in the communities? The humanists and opportunists, are convinced that today any leadership without the mediation of means cannot consolidate. The means, specially the audio-visual ones, have reached in less of a century a superiority as it did not have any emperor in history, as it did not accumulate any other institution in so short time. The radio and the television, both, seduce multitudes. The radio and the television are not enemy sisters to two exceed to them pretending.
\end{abstract}

Key words: Pedagogy, education, human rights, the radio.

Recibido: 16 de marzo de 2009

Aceptado: 17 de abril de 2009

91 Comunicadora Social con énfasis en Comunicación Comunitaria de la UNAD. Tutora de Cátedra, Escuela Ciencias de la Educación, Universidad Nacional Abierta y a Distancia unAD. Especialista en Cultura Política: Pedagogía de los Derechos Humanos, Universidad Autónoma Latinoamericana. Postulada a Maestría en Mediación y Resolución de Conflictos, Fundación Iberoamérica. 
Los informes de derechos humanos realizados por diversas organizaciones nos dan un primer acercamiento al tema de la vivencia de ellos en Colombia. El tema requiere de unas condiciones previas, por ejemplo, la superación de las causas de conflicto, no por vía armada y de la polarización, sino por el contrario, a través de alternativas que respeten la vida, las libertades individuales y las condiciones materiales equitativas y justas de la población, como valores superiores a una comunidad bonita, luchadora y servicial. Ello implica menos plata y esfuerzos para la guerra y un compromiso más decidido y firme con un proyecto económico y cultural que rescate lo digno del ser humano.

Los anteriores aspectos posibilitan una primera lectura frente a la situación de los derechos humanos en Colombia; si inicialmente los abordamos como pilar de la dignidad humana, unos naturales otros de segunda y tercera, cuyo paradigma es el ser humano como centro de la sociedad, los estudios e investigaciones nos dan indicios de su sistemática violación, sumada a las ineludibles consecuencias de inequidad, pobreza y conflictos social en nuestras comunidades.

Sin embargo, frente a las causas y consecuencias de esta situación, diversas organizaciones levantan voces de protesta y se organizan para contrarrestar la situación, al abrir espacios para el desarrollo local, con la presentación de nuevas formas democráticas y de ejercicio de la ciudadanía, entre estas el uso de la radio.

Desde el texto «La Democracia en América Latina, hacia una democracia de ciudadanas y ciudadanos», publicado por el Programa de las Naciones Unidas para el Desarrollo, la búsqueda que las organizaciones sociales de Medellín han emprendido ya hace varias décadas, esa búsqueda que implica avanzar hacia la ciudadanía integral, esa que persigue el goce pleno y efectivo de los derechos civiles, políticos y sociales, debemos pasar de la democracia electoral o electorera a la democracia de ciudadanía.

Es importante registrar en este recorrido algunas apreciaciones teóricas acerca de la sociedad civil, motor de estas reivindicaciones, lo cual nos permite configurarlas luego en la escena local. «Una cuestión que empieza a surgir con fuerza es el desencuentro entre la sociedad civil y la institucionalidad política. Con la democratización crece en importancia la sociedad civil organizada, con nuevos actores sociales, nuevas demandas y nuevas mediaciones. En este proceso se da la ampliación del espacio público y se acentúa la desestatización de la política. Cambia la cultura política y las formas de organización y participación ciudadana, y esto genera tensiones en el seno de las propias sociedades civiles, en la relación entre los movimientos sociales y organizaciones como las ong, o entre movimientos antiguos y nuevos. La vitalidad de las sociedades civiles contrasta con la endémica crisis del sistema político y partidario y con el creciente descrédito de los políticos profesionales y de las formas de representación».

«Se trata de pensar los complejos procesos que mueven por dentro a las sociedades latinoamericanas y que permiten calificarlas como sociedades en situación de construcción de la democracia, como modo de ser y de desarrollarse. Un primer aspecto destacable en este sentido es que las democracias requieren antes que nada sujetos sociales, portadores y constructores efectivos. Es necesario que se creen sujetos históricos que imaginen y deseen 
democracia, que se organicen y luchen por ella, que la constituyan en las condiciones económicas, culturales y políticas existentes».

«La identificación de la sociedad civil como espacio donde construir una participación democrática no es sencilla porque tratándose de América Latina la sociedad civil ha sido históricamente frágil y un espacio de reproducción de las relaciones clientelistas y excluyentes. Pero aunque en gran medida esto sea cierto, los espacios conquistados en la sociedad civil han sido fundamentales para crear tensiones frente a un campo político excluyente».

Este panorama ya nos pone en una dimensión política frente al quehacer de la sociedad civil y nos permite contrastar con lo dinamizado por los movimientos sociales, como lo expresa un importante estudio «Democracia y ciudadanías, balance de derechos y libertades en Medellín» realizado por la Corporación Región, la Escuela Nacional Sindical, Confiar, y la Corporación Viva la Ciudadanía: «tratando de concluir sobre la realidad de algunos de los movimientos sociales en la ciudad de Medellín se pueden resumir los principales aportes del movimiento social a la construcción de democracia y de lo público en la ciudad:

- La formación de ciudadanía

- La ampliación del tejido social diverso

- La formación de una sociedad más plural, tolerante, respetuosa del otro y de lo otro y menos patriarcal

- Los aportes a la deliberación pública

- La disposición y los aportes a la concertación social

- Los aportes a la convivencia y la lucha por la paz

- Los aportes a la planeación del desarrollo y a la formulación de políticas públicas

- La labor de veeduría y control ciudadano».

Y, frente a esto realizan las siguientes apreciaciones:

En muchas ciudades que tienen embolatado el rumbo de la democracia y la ciudadanía, el derecho a la ciudad puede convertirse en un referente muy valioso para la acción política, en tanto contribuye a configurar una mirada integral, compleja e interdependiente de los derechos humanos, mirada que se corresponde con el carácter complejo de la ciudad como espacio de vida individual y colectivo.

De otro lado, al referirnos a la democracia deliberativa, eslabón importante para la acción real de lo público, Habermas propone un modelo de ella «donde la participación activa de la ciudadanía es corolario indispensable del desarrollo pleno del Estado y la justificación de actos ciudadanos, como la desobediencia civil, que como test de constitucionalidad, permitan conciliar la constitución con las nuevas realidades y clamores sociales».

«La noción de democracia es asumida y está necesariamente vinculada al reconocimiento de la ciudadanía y los derechos a todos los miembros de la sociedad [...] un referente obligado al respecto es el clásico trabajo de Thomas H. Marshall sobre los diferentes tipos de ciudadanía y 
de reconocimiento de derechos; para este autor ciudadanía es un estatus que se concede a los miembros de pleno derechos de una comunidad. Son beneficiarios, son iguales en cuanto a los derechos y obligaciones que implica, y distingue tres elementos al hablar de ciudadanía: el civil, el político y el social».

Esto permite corroborar la tesis: el aporte de los «de abajo en la construcción de una sociedad democrática», y además introyectar la reflexión de cara a la ampliación y el fortalecimiento de las organizaciones sociales y comunitarias, y de los espacios y mecanismos para la participación ciudadana. Ya señalamos cómo el conflicto armado, la violencia y la intimidación de los actores armados, y la intolerancia de diversos grupos, incluyendo en ellos al mismo Estado, debilitaron, y en algunos casos acabaron, con diversas organizaciones de la sociedad civil. Este es uno de los mayores costos para la democracia y los derechos de ciudadanía en Colombia. Hoy corresponde al Estado, a los partidos y a la sociedad civil hacer un gran esfuerzo por promover y extender el asociacionismo, fortalecer y democratizar las actuales formas de organización civil, poner a funcionar adecuadamente los espacios para la participación ciudadana, y algo fundamental en materia de libertades cívicas y políticas: respetar los diversos derechos de expresión y las múltiples formas de asociación.

La conformación de organizaciones para la reivindicación social, para la construcción de sujetos y colectividades en cultura política, y el establecimiento de la gobernabilidad como juego social de los públicos organizados ha permitido avanzar en un trabajo que está siendo visibilizado en muchas ciudades y regiones. Unos de los mayores ejemplos en la actualidad es la existencia de la Comunidad de Paz en San José de Apartadó, la Red de Organizaciones Comunitarias de Medellín, las Madres de la Candelaria, quienes con su trabajo van fortaleciendo y consolidando la actividad social y la reivindicación de los derechos ciudadanos.

Pero volvamos a la teoría y exploremos un poco más sobre el concepto de sociedad civil y movimientos sociales, a través de Luis Alberto Restrepo, en El potencial democrático de los movimientos sociales y de la sociedad civil en Colombia «originariamente el concepto de sociedad civil se hallaba asociado a la división que la sociedad romana establecía entre el derecho privado y el derecho público, pero su popularización proviene del liberalismo clásico del siglo XVIII definiéndola como situación y condición que propicia el ejercicio de los derechos ciudadanos».

Por su parte, «los movimientos sociales aparecen como el verdadero tejido que constituye la sociedad civil. Gracias a ello el ciudadano desborda su aislamiento individual y entra en comunicación con otros, compartiendo así puntos de vista, intereses y expectativas que le son comunes. Gracias a ello se crean vínculos de interdependencia entre personas y grupos y generan actitudes solidarias. Desde este punto de vista, constituyen la escuela primaria de la solidaridad social».

Los movimientos sociales son formas colectivas de acción, de amplios sectores de la población, que promueven los intereses y aspiraciones comunes, poseen muy distintos grados de organización, se hacen visibles en el espacio público y el peso de su acción recae sobre 
todos sus miembros quienes participan de manera directa en el escenario público más que sobre unos pocos que aspiren a representarlos; debido a esto se hace necesario «ampliar y consolidar la democracia no sólo como forma política sino también como sistema económico y social, y como cultura que moldea las relaciones cotidianas»».

Frente al concepto es también necesario acudir a unas de las principales vertientes de esta línea de pensamiento, Norberto Bobbio en la obra Estado, gobierno y sociedad: «la sociedad civil es donde pueden encontrarse nuevas formas de legitimación y nuevos espacios de consenso. En la esfera de la sociedad civil se ubica normalmente el fenómeno de la opinión pública entendida como la expresión pública de consenso y disenso, con respecto a las instituciones, transmitida por los medios de comunicación»».

También encontramos a Sidney Tarrow con El poder en movimiento, los movimientos sociales, la acción colectiva y la política: «el poder de los movimientos se pone de manifiesto cuando los ciudadanos corrientes unen sus fuerzas para enfrentarse a las élites, a las autoridades y a sus antagonistas sociales. Crear, coordinar, y mantener esta interacción es la contribución específica de los movimientos sociales, que surgen cuando se dan las oportunidades políticas para la intervención de agentes sociales que normalmente carecen de ella. En su base se encuentran las redes sociales y los símbolos culturales a través de los cuales se estructuran las relaciones sociales [...] se crea un movimiento social cuando explotan sentimientos enraizados y profundos de solidaridad o identidad».

Ahora sí entremos en materia del porqué medios tan importantes como la radio se convierten en una herramienta pedagógica para el fortalecimiento de la cultura política y su aplicabilidad como pedagogía para los derechos humanos.

Preguntémonos, ¿por qué la radio como instrumento pedagógico y político? El recorrido lo haré desde el texto, «Onda cheverísima. Comunicación para la convivencia», recreando lo que ha sido el origen de la radio y sus aportes.

\section{El origen}

En el año 1920 apareció oficialmente la radio, y poco a poco se desarrolló al ofrecer programas, comentarios, mensajes, transmisiones deportivas y música con artistas que cantaban en vivo y en directo, antes que se inventaran los discos.

Cuando los pioneros de la radio descubrieron que se podía transmitir el sonido a través del espacio, comenzó la moda de la radio como medio para comunicar masivamente toda clase de mensajes, para difundir ideas, para ganar dinero. Nacen así las empresas de radio. De esta manera, se comenzó a llenar el espacio de ondas que llevaban y traían mensajes, noticias, humor y música. 
En los años siguientes, se reglamentó la radiodifusión y la publicidad radial comenzó a hacer sentir su peso. Los programas informativos ganaron muchos simpatizantes y la competencia entre la radio y el periódico se inicia.

En 1927 se establecieron normas para el manejo de los espacios radioeléctricos, con el fin de evitar interferencias entre las mismas emisoras. Al mismo tiempo de la proliferación de las emisoras, comenzó la gran producción de radiorreceptores. Para 1930, se calcula que en Estados Unidos había trece millones de receptores y en Europa ocho millones. La competencia entre la prensa y la radio obligó a muchos medios a trabajar con creatividad. La radio contrata cantantes, se forman archivos grabados con buena música y se transmiten recitales y conciertos.

\section{Modalidades de la radio}

En Europa fueron los gobiernos quienes se apropiaron de las emisoras, al ver el impacto en la sociedad; así surgieron las grandes emisoras estatales cuyos mensajes eran controlados.

José Ignacio López Vigil, en su texto Manual urgente para radialistas apasionados nos expresa: «Tenía apenas 21 años. Un día, en su casa de Bolonia, Guglielmo Marconi hizo sonar un timbre en el sótano apretando un botón situado en la buhardilla. Lo sorprendente era que entre ambos puntos no había ninguna conexión.

Poco después, en las afueras de la ciudad, el joven investigador italiano daba una instrucción simple a su ayudante:

— Si suena tres veces, dispara una.

El muchacho corrió detrás de una colina con el receptor inalámbrico y una escopeta. Desde su laboratorio, con un primitivo transmisor de ondas hertzianas, ${ }^{92}$ Marconi pulsó los tres puntos de la letra $\mathrm{S}$ en aquel alfabeto morse que había aprendido hacía muchos años de un viejo telegrafista ciego. Al instante, como por arte de magia, se escuchó el disparo convenido. La telegrafía sin hilos, madre de la radio, había sido inventada». ${ }^{93}$

Esto ocurrió en 1895. Un par de años más tarde, conectando una antena al transmisor, Marconi logró proyectar su señal a mil metros de distancia. Después, alargando la longitud de onda, superó los dieciséis kilómetros del Canal de la Mancha. En 1901, como un corredor después de entrenarse para el gran salto, cubrió los 3300 kilómetros que separan Inglaterra de Terranova,

92 En 1887, el sabio alemán Heinrich Hertz había demostrado la existencia de ondas electromagnéticas capaces de transmitir energía sin necesidad de cables, en forma de campos eléctricos y magnéticos alternos. En junio de 1896, el profesor ruso de matemáticas Alejandro Popov, en un experimento independiente, transmitió un mensaje por telegrafía sin hilos a 250 metros de distancia.

93 Como si Marconi lo presintiera, el 14 de abril de 1912 el Titanic hizo un desesperado sos a través de su recién estrenado equipo de telegrafía sin hilos y se pudieron salvar setecientas vidas del naufragio. De ahora en adelante, todo barco iría provisto de una estación marconi. 
en Canadá. Los nuevos telegramas volaban libres. Podían prescindir de los cables y de los postes terrestres. ${ }^{94}$

La wireless, la sin hilos, como se le comenzó a llamar al nuevo invento, unía tierras y mares, saltaba montañas, desparramaba los mensajes a través del éter, sin ningún otro soporte que las mismas ondas electromagnéticas. Todos los que dispusieran de un receptor adecuado, podían captarlas, pero no entenderlas, porque los breves mensajes enviados tenían todavía que ir cifrados en alfabeto morse.

En la nochebuena de 1906, el canadiense Reginald Fessenden realizó la primera transmisión de sonido: los radiotelegrafistas de los barcos que navegaban frente a las costas de Nueva Inglaterra no captaron esta vez impulsos largos y cortos en clave morse, sino una voz emocionada leyendo el relato del nacimiento de Jesús y acompañada por un disco de Haendel. Fessenden había logrado emitir directamente la voz humana sin necesidad de códigos, pero su proeza apenas alcanzaba un kilómetro y medio a la redonda. ¿Cómo amplificar la voz, cómo superar esa última barrera que liberaría para siempre al sonido?

Al año siguiente, en 1907, Alexander Lee de Forest, norteamericano, descubre unas válvulas de electrodos que transforman las modulaciones del sonido en señales eléctricas. ${ }^{95}$ Estas ondas, transmitidas de una antena a otra, podían ser reconvertidas nuevamente en vibraciones sonoras. Con estos tubos de vacío, que servían igualmente para enviar o recibir, nacía la radio, tal como la conocemos hoy: sin distancias ni tiempo, sin cables ni claves, sonido puro, energía irradiada en toda dirección desde un punto de emisión, y recibida desde cualquier otro punto, según la potencia de las válvulas amplificadoras.

Ahora sí. Ahora estaban dadas las condiciones para comenzar a hacer radio. En América Latina, los argentinos tomaron la delantera. El médico Enrique Susini y un grupo de entusiastas amigos montaron un transmisor de 5 vatios en la azotea del teatro Coliseo. Desde allí hicieron las primeras pruebas. El 27 de agosto de 1920 a las 9:00 p. M., los locos de la azotea, como ya les llamaban, transmitieron para todo Buenos Aires una ópera de Richard Wagner. Este fue el primer programa de radio dirigido a público abierto que se oyó en nuestro continente. ${ }^{96}$ En esos mismos días, en Montevideo, Claudio Sapelli, un trabajador de la General Electric, escribió a Lee de Forest pidiéndole una de aquellas válvulas mágicas y comenzó a transmitir desde otra azotea, la del Hotel Urquiza. Por todas partes era la misma efervescencia de probar y comprobar el asombroso invento.

\footnotetext{
94 Lee de Forest experimentó con el tubo desarrollado por el inglés John Fleming, añadiendo una rejilla entre el filamento y la placa.

95 Carlos Ulanovsky, Días de Radio, Espasa Calpe, Argentina, 1996. pp. 18-24.

96 El electroimán de la cabeza grabadora magnetiza la cinta de plástico recubierta de una capa de óxido de hierro al pasar frente a ella. El sonido queda almacenado electromagnéticamente en la cinta. Al reproducirlo, los impulsos magnéticos de la cinta se convierten en acústicos y se amplifican.
} 
La primera emisora con servicio regular fue la KDKA de Pittsburgh, instalada en un garaje de la Westinghouse. El 2 de noviembre de 1920, el popular radioaficionado Frank Conrad daba a conocer los votos obtenidos por Warren Harding y James Cox, candidatos a la presidencia de los Estados Unidos. A partir de ahí, el éxito de la radio fue imparable. En 1921, se inician en París los primeros programas, utilizando la Torre Eiffel como antena. Al año siguiente, en 1922, se funda en Londres la BBC. Pocos meses más tarde, salen al aire las primeras transmisiones españolas. En la recién creada URSS, Lenin exhorta a la investigación y aprovechamiento de aquel periódico sin papel y sin fronteras, como él llamaba a la radio. Por todas partes se estrenan emisoras y se venden aquellos primeros equipos de galena, todavía sin parlantes, para escuchar a través de audífonos. En 1924, había más de seis millones y medio de receptores en el mundo. La radio se expandió como ningún medio de comunicación lo había logrado hasta entonces.

En 1945, un nuevo descubrimiento cambiaría la forma de trabajo en las numerosas y pujantes emisoras. Con el magnetófono se podían hacer montajes previos al momento de la emisión. Más que ensayar antes de la función, como se hacía en el teatro, la radio podía darse ahora el lujo de enlatar efectos de sonido, grabar y borrar, añadir fondos musicales, separar unas voces de otras, descansar la programación con espacios en directo y en diferido. La cinta magnética permitía una flexibilidad que los discos de acetato nunca ofrecieron ${ }^{97}$. Si la transmisión del sonido ya estaba liberada, las nuevas grabadoras liberaban la otra punta del sistema, el momento de la producción radiofónica. Al fin, después de un galopante siglo de inventos e inventores, el sonido podía sonar tranquilo y orgulloso. La radio lo había hecho tan indispensable como la luz eléctrica o el agua corriente.

Y, fue entonces cuando la radio se creía dueña y señora de casa, que le nació una hermanita engreída y codiciada por todos: la televisión.

Hasta entonces, la radio había ocupado el centro. En torno a ella, tres generaciones se sentaron a oír las radionovelas lloronas y las noticias inquietantes. Con la radio se cantaba, con la radio se jugaba, la radio había cambiado los horarios del quehacer doméstico y del descanso nocturno. Ella era la verdadera reina del hogar. ¡Y ahora, la televisión! Celosa por la recién llegada, la radio se sintió insegura, perdida. Se sintió vieja y relegada. Quienes antes vivían pendientes de sus invisibles labios, comenzaron a reunirse en torno a la pequeña pantalla para mirar en ella los culebrones y los concursos que antes sólo podían escuchar. La radio fue desplazada y en su lugar se entronizó la televisión.

En ese momento de humillación - como ocurre en los cuentos que ella misma había difundido - apareció un hada madrina que le dio a beber un elíxir de juventud. La radio lo apuró de un sorbo.

97 El 1 de julio de 1948 la firma norteamericana Bell Telephone Laboratories anuncia el sensacional descubrimiento del transistor, punto de partida para el desarrollo de la electrónica. Los descubridores del transistor John Bardeen, Walter Brattain y William Shockley fueron galardonados con el premio Nobel. 
El elíxir se llamaba transistor. ${ }^{98}$ Con aquel descubrimiento de la Bell Telephone Laboratories, en 1948, ya no hacían falta los tubos amplificadores de Lee de Forest. Los nuevos semiconductores de silicio reducían el tamaño tanto del equipo transmisor como del receptor, y mejoraban la calidad de las emisiones. Con los transistores y las pequeñas baterías secas, la radio cortó el fastidioso cordón umbilical que la ataba desde su nacimiento a la toma de corriente alterna. No más cables para la recepción. La radio ahora cabía y se trasladaba en un bolsillo, en una cartera. Como cuando se pasó del reloj de pared al de pulsera, la nueva radio portátil se volvió disponible en todo lugar y momento, de día y de noche, desde la ducha hasta el automóvil, para quien va de paseo y para quien se mete con ella en la cama.

La radio cambió responsabilidades. Dejó de ser espectáculo familiar para ubicarse como compañía individual.

Desde un comienzo se desarrollaron en Estados Unidos las emisoras privadas que hoy conocemos como comerciales, con ánimo de lucro. Hoy son las transnacionales de la comunicación.

En América Latina, hacia 1950, con la aparición de los transistores, la radio se puso al alcance de personal de bajos recursos, incluyendo los campesinos que no tenían energía eléctrica en sus comunidades. Ahí comenzó la nueva historia de la radiodifusión y surgieron las emisoras educativas.

El nacimiento de las radios educativas en América Latina no se dio en todos los lugares por igual. En cada sitio sus necesidades las hicieron surgir. Veamos algunas claves que impulsaron la radio educativa, comunitaria y emisoras escolares.

\section{Historia y contexto de las radios educativas, comunitarias y emisoras escolares en América Latina y Colombia}

- La pionera en nuestro continente fue la desaparecida Radio Sutatenza, nació en Colombia en 1948 y emitió durante cuarenta años; llegó a ser la más importante del país. A partir de esta experiencia surgieron escuelas radiofónicas en toda América Latina que se centraron en la Educación Abierta y a Distancia, por radio.

- En 1952 nacieron en Bolivia las Emisoras Mineras. Fueron llevadas por los sindicatos mineros que luchaban por la reivindicación de estos sectores populares.

- En los años setenta surgieron, además, otras experiencias de radio en poblaciones con dificultades sociales y políticas, especialmente en Centroamérica, emisoras que se conocieron con el nombre de emisoras subversivas.

- En esta misma década aparecieron nuevas emisoras en el continente cuya finalidad eran los movimientos indígenas, campesinos, feministas, ecológicos. Fueron algunas emisoras

98 Las cifras de la investigación son elocuentes. En promedio, los chilenos escuchan cerca de cuatro horas en el hogar, una hora y media en el trabajo y casi media hora en automóvil o en transporte colectivo. El 97\% de la población oye radio, el $84.1 \%$ lo hace a diario y sólo el $2.9 \%$ asegura no escucharla. En cuanto a los programas preferidos, la música ocupó el primer lugar con el 98\%. Las noticias recibieron el 75.1\% superando al deporte, que recibió el 43.5\%. Los espacios con animador en vivo recibieron el 51.7\%. RadioWorld, 18 septiembre 1996, volumen 20 , número 19. 
con mucha potencia y de cobertura regional que se conocían como emisoras populares; pero también aparecieron emisoras de pequeño alcance, especialmente en Argentina, conocidas como comunitarias.

- En los años noventa en Colombia, por la nueva constitución, se dio apertura a emisoras de alcance municipal, conocidas como radios comunitarias, el país volvió a ser pionero de América Latina, esta vez por tener una legislación que favorece las emisoras locales de propiedad comunitaria con finalidades diferentes al lucro y a la empresa privada.

- Desde hace diez años viene un auge de las experiencias de programas infantiles y juveniles en las emisoras culturales, populares y comunitarias en el continente y junto a estas experiencias comienzan a surgir emisoras escolares en los establecimientos educativos inspiradas en las propuestas de lectura crítica de los mensajes de los medios masivos de información y de percepción activa que los docentes y jóvenes reciben en multitud de capacitaciones en el uso de los medios en el aula, a lo largo y ancho de América Latina, incluyendo las experiencias de Brasil y de España.

- En Colombia, en los mismos años noventa, especialmente en las ciudades capitales como Bogotá, Barranquilla, Medellín, el uso de equipos de amplificación de las instituciones educativas surge como el lenguaje apropiado por los jóvenes para hacer, del aula y de los establecimientos educativos, una emisora donde los mismos chicos y chicas manejan los equipos, hacen programas noticiosos, complacencias, avisos, llamándose a estos usos del equipo de amplificación: emisoras escolares.

- Ha existido una variedad de experiencias en nuestro país: programas radiales infantiles en emisoras comerciales, como «Colorín Coloradio», generalmente patrocinados por empresas comerciales, donde los chicos son el objetivo de la emisión; franjas sobre programas para niños en emisoras culturales y estatales, como la radiodifusora nacional; experiencias exitosas como PCIN (Proyecto de Comunicación para la Infancia), «Alharaca» y «Zona Común», producciones radiales que recogen las diversas experiencias a lo largo de todo el país.

- En las radios comunitarias es donde los niños y los jóvenes se apropian de programas y se suben al espectro radioeléctrico, y son ellos los sujetos productores y protagonistas de estos espacios. Emisoras locales como San Vicente de Chucurí, Íquira Estéreo, Montes de María en Bolívar, escuela Andariega en Tibasosa, experiencias de Sogamoso, Monterrey, Red de Reporteritos de la Paz de Orito, Red de Emisoras Escolares de Puerto Asís y Radio Ocaina Stéreo de Putumayo hablan de una nueva forma de apropiación del lenguaje radiofónico por parte de los estudiantes en emisoras que incursionan en el dial como las experiencias de Radio UPA, en el Salvador, «Prohibido para mayores» en Radio Sucumbios, «Garabatitos» e «Inquietudes» de Radio Latacunga, en Ecuador, Radio Sur 90.1 en Córdoba, Argentina, entre otras.

Pero son los patios de los colegios, de las instituciones oficiales, las aulas, el salón de música y las rutas de los transportes escolares de los colegios privados los que se convierten en «nuevas ondas», donde es posible escuchar otras voces, nuevos rostros, otros protagonistas, otros «locutores» y otros temas. Nacen REDES de Radio Escolar en el sur. (I Encuentro de Radios Escolares, 2 de junio de 1999) pero también, en el norte. Y hoy se animan y se comienzan a enlazar experiencias de nuevos NODOS, como el de «Onda cheverísima» con la presencia de veinticinco colegios distritales de nueve localidades de Bogotá y «Pongámonos en Onda», 
que reúne diez instituciones educativas de la localidad de Kennedy, todos con la ilusión de tejer redes y democratizar la palabra, la comunicación, y la esperanza.

Recuerdo la primera cuña que grabé para una emisora campesina: se oían ladridos y un locutor preguntaba sobre el mejor amigo del hombre. Una locutora respondía: el perro no ... ¡la radio! $\mathrm{Y}$ es que con el transistor, la radio se convirtió en fiel compañera de hombres y mujeres, de sanos y enfermos, de choferes y caminantes, de cocineras y empleadas domésticas, de bañistas en la playa, de fanáticos que ven el partido en el estadio y lo oyen al mismo tiempo con el aparatito pegado a la oreja, de los vendedores ambulantes, de los campesinos que la cuelgan del arado, de oficinistas y estudiantes, de los insomnes que la sacan al balcón. Casi todo lo que hacemos en nuestra vida puede acompañarse con la radio. Sobre todo, el amor.

\section{¿Con los días contados?}

Cuando un periodista joven hace una entrevista, nunca falta la pregunta de cajón: Y la radio... ¿todavía tiene futuro? ¿Cómo se defiende frente a la televisión? Me hace gracia esta presunción del medio radiofónico con los días contados. En la edición internacional de RadioWorld se lee lo siguiente: «Un estudio realizado por la Pontificia Universidad Católica de Chile, una de las entidades de educación superior más respetadas del país, ha dejado a la radio en muy buen pie: el estudio demostró que la radio concentra niveles superiores de recepción que la televisión, en ambos sexos y en todos los sectores socioeconómicos (el 62.1\% de los chilenos dedica más horas a escuchar radio que a ver televisión). Además, el estudio mostró que el público asigna mayor credibilidad a la radio.» ${ }^{99}$

Si se hiciera la misma investigación en otros países de la región, sospecho que obtendríamos resultados similares. Además, a los agoreros de otros medios hay que mostrarles las cifras: nunca estuvieron más saturados los diales, nunca hubo más estaciones y receptores de radio en nuestros países ${ }^{100}$. Ningún medio de comunicación tiene tanta penetración como la radio, pues alcanza prácticamente a toda la población latinoamericana y caribeña. ${ }^{101}$

Hoy se escucha más radio que en los años cincuenta. Lo que pasa es que también se ve más televisión. Se ven más películas (aunque no sea en el cine), se habla más por teléfono, se

99 Ecuador, con trece millones de habitantes, cuenta con setecientas emisoras de radio. El número de las FM ha crecido en $345 \%$ respecto a la cifra de 1994.

100 El inventario de medios de comunicación realizado por CIESPAL en 1993 da cuenta de 315 aparatos receptores de radio y 142 de televisión por cada mil habitantes. Estas cifras ya han aumentado. pp. 144 y 392.

101 Rafael Roncagliolo: La radio sigue siendo el medio de comunicación más universal. Puede decirse que los ciudadanos se enteran de las noticias por la radio, las confirman por la televisión y las reflexionan, al día siguiente, con el diario... Tal especialización explica que no haya habido reemplazo de la radio por la televisión, como no lo hubo cabalmente del cine por la televisión ni del teatro por el cine, ni del libro por el periódico... La historia de los medios registra sumatorias y especializaciones, no desplazamientos mecánicos. Y la especialización ha hecho de la radio contemporánea el único medio que tiene permeabilidad absoluta y requiere de la participación sincrónica, en vivo, de los oyentes. El lenguaje de la radio, ponencia presentada en el Primer Congreso Internacional de la Lengua Española, Zacatecas, México, abril 1997. 
navega más en internet, se consumen más horas que nunca accediendo a todos los medios que estén a nuestro alcance. Cada uno tiene su originalidad, su espacio ganado en la vida diaria, sus ventajas y limitaciones, sus fanáticos y detractores. Pero todos coexisten.

Como bien dice Rafael Roncagliolo, los medios de comunicación no se suplantan, sino que se reacomodan. ${ }^{102}$ Sucede lo del visitante que llega tarde, buscamos una silla más y el círculo de amigos y amigas se agranda. Nadie se va, todos se acondicionan en el salón. Cuando la radio nació, fue la prensa escrita la que se llenó de celos y se preocupó por el nuevo medio que ofrecía una mayor inmediatez informativa. Tanta fue la indignación de los periódicos, que prohibieron a la radio tomarlos como fuente informativa. Prohibieron a las agencias de prensa vender información a las emisoras. Desesperados, intentaron aprobar leyes que impidieran a la radio transmitir noticias. Naturalmente, de nada sirvieron estas intolerancias.

Fue precisamente la Segunda Guerra Mundial la que puso de manifiesto la importancia informativa de la radio. El público estaba ávido por saber los acontecimientos y no iba a esperar a la mañana siguiente para conocerlos en los periódicos. La radio brindaba noticias calientes, había arrebatado para siempre la primicia informativa. Ante esto, los periódicos reacomodaron sus funciones y descubrieron una nueva responsabilidad de análisis, de confirmación de los hechos, de interpretación de un mundo confuso y complejo.

De la misma manera, cuando la televisión aparece, la radio se reacomoda y, como ya dijimos, cambia de espectáculo familiar a compañía individual.

- ¿Por qué le gusta tanto oír radio, señora?

- Porque me trae el vecindario a casa.

Para acompañar la soledad y para amenizar la compañía, para informarse cuanto antes de lo que pasa y para olvidarse lo antes posible de lo que pesa, así es la radio, como esos vehículos todo terreno: para toda situación.

Para colmo de bienes, la radio, ya rejuvenecida por la movilidad que le brindó el transistor, se embelleció aún más con el desarrollo de la $F M$ - una nueva franja del espectro de menor alcance pero mayor calidad, especialmente para las emisiones musicales - y con la estereofonía.

Actualmente, la radio goza de excelente salud. La emisión a través de las nuevas frecuencias digitales (DAB), la difusión ya no sólo por ondas hertzianas, sino por fibra óptica y satélite, la recepción de alta fidelidad con equipos también digitalizados, hacen que la radio participe plenamente en la revolución de las nuevas tecnologías y en el universo multimediático. Cada vez más emisoras colocan su programación completa, 24 horas y tiempo real, en internet. Con un receptor pequeño, a pilas, se captan vía satélite docenas de canales con señales multimedia. ${ }^{103}$

102 Proyecto WorldSpace, RadioWorld, 16 octubre 1996, volumen 20, número 21.

103 Lluís Bassets, De las ondas rojas a las radios libres. Gustavo Gili, Barcelona, 1981, p. 55. 
En cuanto a las grabaciones digitales, estas eliminan todos los ruidos espurios y permiten sacar copias, y copias de copias, sin perder la menor calidad de una generación a otra. El DAT, los minidisc y la grabación directa al disco duro de la computadora, sustituyen aceleradamente al magnetófono.

Nunca como hoy se cumple la sentencia de Bertolt Brecht: «de repente, se tuvo la posibilidad de decirlo todo a todos». Ojalá no se cumpla su segunda parte: «...pero, bien mirado, no se tenía nada que decir.». ${ }^{104}$

\section{Nuevos roles de los medios}

La radio le cambió el libreto a la prensa. La televisión se lo cambió a la radio. Y hoy, la globalización de la cultura y la revolución tecnológica se lo ha cambiado a todos los medios de comunicación masivos.

Lo cierto es que los medios de comunicación siempre estuvieron en medio de la vida. La gente se congregaba en torno a un libro de cuentos, o a una pantalla de cine, o a una radiola. ¿Qué es lo nuevo, ahora? ¿Cuál es el protagonismo que han ganado los medios, especialmente los masivos?

\section{Veamos esta significativa encuesta realizada por el ICP/Research:}

¿En quiénes creen los latinoamericanos? Respecto a los parlamentos, la opinión es pésima: apenas el $9 \%$ de los guatemaltecos y el 11\% de los ecuatorianos tiene confianza en el suyo. Los venezolanos y colombianos le conceden un poco más de crédito (17\%). En cuanto a los partidos políticos, los más benevolentes son los mexicanos y los costarricenses (27\%). Los peruanos y bolivianos tienen porcentajes bajísimos (13\%). Lo mismo ocurre con los jueces, con los sindicatos, la policía, los empresarios, los presidentes, con el sistema político y económico en general. El vacío lo llenan las iglesias, que siguen cosechando un buen puntaje (el 61\% de los latinoamericanos cree en ellas). Y los medios de comunicación: dos de cada tres ciudadanos de nuestros países están convencidos de la verdad de lo que dicen y muestran la prensa, la radio y la televisión. ${ }^{105}$

¿Qué significa esto? Al menos, tres nuevos roles de los medios de comunicación social. Vale la pena detenerse en cada uno de ellos antes de emprender el camino urgente para mejorar nuestra producción radiofónica: ${ }^{106}$

104 Citada por Eleázar Díaz Rangel en el número 54 de la revista Chasqui, junio de 1996, pp. 68-69.

105 Estas ideas están desarrolladas en Un nuevo horizonte teórico para la radio popular en América Latina, ALER, Quito, 1996.

106 Rosa María Alfaro: Cuando un medio masivo retrata la realidad, también la legítima. La radio legitima realidades, temas, personajes, actores, en el ámbito público. Es decir, quienes salen por la radio adquieren notoriedad, se les conoce públicamente, son valorados y reconocidos como importantes. Pasan de ser sujetos privados a públicos, de personas se convierten en actores sociales. La interlocución radiofónica, UNDA-AL, Quito, 1994, p. 78. 


\section{Legitiman lo que transmiten}

En 1997, la entonces ministra de educación del Ecuador, Sandra Correa, con un juicio político pendiente por haber plagiado nada menos que su tesis doctoral, tomó un avión y - previo despliegue publicitario - viajó a Calcuta para hacerse bendecir por la moribunda Madre Teresa. De esta manera, demasiado burda, la ministra pensaba legitimarse ante el religioso pueblo ecuatoriano.

¿Qué significa legitimar? Garantizar la autenticidad de algo o de alguien, su conformidad con la ley. El hijo legítimo es el reconocido como tal por sus padres. Quien legitima a otro, le agrega valor, le concede importancia.

Tradicionalmente, algunas instituciones legitimaban a las personas: la escuela, la universidad, la Iglesia, el ejército, el Estado. Si tenías un diploma o un cargo público, ascendías socialmente. El problema era que los estudios o los rangos no se notan en la cara. El asunto, como vimos, es que estas mismas instituciones legitimadoras han perdido credibilidad, especialmente las políticas. Difícilmente puede acreditar a terceros quien no tiene crédito propio.

Los medios de comunicación sí legitiman, porque el público cree en lo que oye y ve a través de ellos. La gente confía, tiene fe en las palabras e imágenes que presentan. Los medios avalan hechos, situaciones, opiniones y personas. Aparecer en radio o en televisión reviste con un uniforme más llamativo que el de cardenales y coroneles, da más apariencia porque la pantalla y el micrófono hacen visible y audible ante miles, ante millones de personas. Más ancho y ajeno es el mundo, más prestigio brindan los medios.

Hace unos años, en el suroeste dominicano, la Iglesia católica se había encargado de perseguir el vudú criollo, los populares palos del Espíritu Santo. Para proteger a la población contra esta herejía, algunos curas hasta decomisaron los tambores con que los líderes religiosos hacían sus ritos. En Radio Enriquillo teníamos una flamante unidad móvil y se les ocurrió ir a cubrir una de aquellas veladas nocturnas, medio clandestinas, donde los antiguos dioses africanos se montan sobre los devotos al ritmo trepidante de los atabales.

Cuenta: «Subimos a la loma del Granado y transmitimos la ceremonia de Dermirio Medina, el guía religioso de la comunidad. Al día siguiente, de mañanita, ya nos estaban lloviendo los papelitos y las visitas de decenas de grupos de paleros que solicitaban la presencia de la móvil para acompañar sus veladas. Todos querían aparecer en la emisora. Y no lo hacían por figureo, sino como reivindicación social. La iglesia romana los había censurado, descalificado. La radio los valoraba.

«-La móvil está en otro lado — me tocó excusar-, no podemos transmitir la velada de Vicente Noble.

-No importa - insistían los paleros-, pero vengan. Que la gente vea que aquí están "los de la radio".»" 
Sonando o muda, la presencia de la emisora los legitimaba. La camioneta de la radio quedaba ahí, frente al bohío ceremonial. Y comenzaban a repiquetear los tambores de la fiesta.

«-Ya somos famosos — escuché decir a una cofrada—. ¡Hasta el Barón del Cementerio habrá escuchado!»

La palabra es sugerente: fama viene de una raíz griega que significa brillar. Los medios de comunicación, como el rey Midas, hacen relucir todo lo que tocan ${ }^{107}$.

\section{Establecen la realidad}

La conclusión de lo anterior podría resumirse así: lo que los medios sacan a la luz pública, al sonido público, queda valorado. Lo que sale, vale. Y aún más: sólo lo que informa, existe.

Isaac Azimov explica cómo, en aquellos tiempos remotos, la mayoría de los seres humanos, dedicados a la agricultura o al pastoreo, ignoraban por completo lo que ocurría más allá del primer cerro, muchos de ellos ni siquiera sabían a cuál imperio pertenecían. Se contentaban simplemente con vivir y morir en su terruño y, en ocasiones especiales, desplazarse desde la propia aldea a la vecina. Los mercaderes y los soldados eran los únicos que sabían de otros pueblos, que visitaban las tierras sin nombre, más allá del horizonte. Cuando estos viajeros regresaban, relataban cosas asombrosas, aventuras con cíclopes gigantes y monstruos marinos. Sólo ellos los habían visto y oído, y había que darles fe. Lo que contaba Marco Polo a la vuelta de sus andanzas, era lo cierto. Y lo que no contaba, no existía ${ }^{108}$.

Hoy, en nuestra aldea global, después de tantos siglos y tantos avances científicos, pasa algo parecido. Los medios de comunicación son los nuevos promotores de la realidad, ¿o de la fantasía? Lo que no sale en la pantalla o por los micrófonos, es como si no hubiera ocurrido. Lo que los medios afirman, afirmado queda. Lo que ignoran, no existe.

Estamos acostumbrados a decir que los medios de comunicación dan a conocer lo que sucede en nuestro país y en el mundo. En sociedades más pequeñas, prevalecían otros espacios para intercambiar información, desde la cantina hasta la plaza del pueblo, desde el mercado hasta la misa de los domingos. En Bolivia, los habitantes se enteraban de todo y se encontraban con todos en el Prado, subiendo y bajando por la avenida Santa Cruz. Ahora no. Ahora la plaza es el set de televisión y la cabina de radio. Antes, los periodistas corrían tras los políticos. Ahora es al revés. Los políticos se apersonan en los canales, mendigan una entrevista, siempre están disponibles hasta para un reportero de segunda. Es que los medios crean el escenario donde se da razón del mundo y sus vaivenes. Quien sube a las tablas, queda enfocado, iluminado. Quien no lo logra, permanece en penumbras.

107 Isaac Azimov, El Universo. Alianza Editorial, Madrid, 1973. p. 11.

108 Lo mismo podría decirse de la escena cultural, religiosa, social, económica. Nunca fue tan actual la intuición de Calderón de la Barca con su Gran Teatro del Mundo. 
En dicho escenario se monta lo que se ha denominado la escena política: los medios eligen los actores (asignando papeles, quién es el protagonista y quién el antagonista); escriben el argumento y provocan el desenlace. ${ }^{109}$

Ensanchar el escenario, presentar los más variados puntos de vista. El pluralismo de opiniones dentro del medio, y el pluralismo de medios dentro de la sociedad aseguran la democracia y desarrollan la inteligencia humana.

\section{Representan a los ciudadanos}

Quien sale una vez, vale. Quien sale mucho, vale mucho. Y con tanto valor agregado, locutores y locutoras, comunicadoras y periodistas, ya no sólo hablan en público, sino en nombre del público.

Nadie los eligió para dicha representación, pero ahí están ellos y ellas, sonrientes y aceptados, ocupando la silla vacía que dejaron líderes políticos y sindicales, jerarquías y gobernantes venidos a menos por haber tomado parte en el botín fácil de la corrupción. La gente ha endosado a los medios la confianza perdida en tales dirigentes.

Como representantes de la ciudadanía, los medios se convierten en mediadores entre esta y el poder. Abanderando causas nobles o plegándose a quien más paga, la radio, la televisión y la prensa se dan cita, casi sin excepción, en medio de todos los conflictos sociales. Los medios destapan escándalos, fiscalizan a las autoridades, les recuerdan sus promesas de campaña, defienden los derechos del consumidor, resuelven problemas cotidianos, desde el barrio que se quedó sin luz hasta el radiotón para la navidad de los niños.

En los medios, se reúne el gobierno con la oposición, se presentan las más variadas tendencias políticas. En las emisoras y televisoras democráticas, dialoga el alcalde con los vecinos, se confrontan los empresarios y los obreros, los funcionarios y los usuarios, hablan todos los sectores, amigos y enemigos, de arriba y de abajo, de derecha, izquierda y centro. ¿Qué otro espacio social tiene tal convocatoria y pluralidad? Ni siquiera el templo. ¿Dónde podemos juntar tantos intereses contrarios y puntos de vista diferentes? Los medios se han convertido en el principal lugar de encuentro e intercambio, punto de reunión obligatorio para todos aquellos que quieren vivir civilizadamente. En los sets y en las cabinas se hacen alianzas, se construyen adhesiones y consensos, se logran negociaciones, se debate con todos y todas sobre todo. La opinión pública gravita en torno a estos espacios de mediación social. Desde hace años se viene hablando de la prensa como el cuarto poder. Tal como van las cosas, quizás ya sea el primero. O el trampolín para el primero.

¿Nos representan quienes dicen hacerlo? ¿Cómo distinguir, más allá de las luces del teatro, las máscaras y los rostros, las voces que recitan libretos aprendidos y las que hablan con sinceridad? No resulta fácil para el público, muchas veces encandilado ante lo que ve y oye.

109 Jesús Martín Barbero, De los medios a las mediaciones. Gustavo Gili, Barcelona, 1987. 
Tampoco resulta optativo para los mismos actores que, quieran o no, deben salir a escena. Unos y otros, humanistas y oportunistas, están convencidos que hoy no puede consolidarse ningún liderazgo sin la mediación de los medios.

Los medios, especialmente los audiovisuales, han alcanzado en menos de un siglo una preponderancia como no tuvo ningún emperador en la historia, como no acumuló ninguna otra institución en tan corto tiempo. La radio y la televisión, ambas, seducen multitudes. La radio y la televisión no son hermanas enemigas ni tienen que rivalizar por la zapatilla de la cenicienta. A las dos les sobran pretendientes. En nuestro caso - y el de ustedes, lectoras y lectores, y el de quien escribe - nos prendamos de la más madurita. Nos declaramos apasionados y apasionadas por la radio.

De esta manera culmino este escrito visto desde diversas posturas académicas e ideológicas que nos permiten abordar los temas que se pueden desarrollar a partir de la radio. Con ella podemos mostrar caminos que en teoría han sido recorridos y discutidos muchas veces pero que, para las organizaciones, se pueden convertir en el medio para llevar la cultura en pedagogía para los derechos humanos y la sana convivencia, como una conquista del ser social, en condiciones de vida digna, con la vivencia de lo público como una posibilidad para el desarrollo con justicia y equidad.

Teniendo en cuenta lo expuesto, ¿consideran ustedes que a través de este medio de comunicación pueden materializarse propuestas educativas que lleven al fortalecimiento de la convivencia, la tolerancia y el respeto en todas las comunidades? Todas las radios tienen una misma propuesta: la participación popular, lo expresa Roland Barthes «que la gente hable, hablando. Nada nos humaniza más que la Palabra».

\section{REFERENCIAS BIBLIOGRÁFICAS}

BARBERO, Jesús Martín. De los medios a las mediaciones. Barcelona: Gustavo Gili. 1987.

BOBBIO, Norberto. Estado, gobierno y sociedad. México: Fondo de Cultura Económica. 1985.

LÓPEZ VIGIL, José Ignacio. Manual urgente para radialistas apasionados. Lima. 2005.

MEDINA, Jorge Arturo y CASTAÑO, Luz Stella. Democracia y ciudadanías, balance de derechos y libertades en Medellín. Medellín: Pregón Ltda. 2005.

NOTAS DE LOS MÓDULOS. Los DD. HH. en Colombia, Sociedad Civil, Estado y Constitución Política. Especialización en Cultura Política: Pedagogía de los DD. HH. Medellín: Universidad Autónoma Latinoamericana. 2008.

ONDA CHEVERÍSIMA. Comunicación para la Convivencia. Sintonizando Redes de Radio Escolar. Alcaldía Mayor de Bogotá, D. C. Bogotá: Paulinas, Centro de Comunicación Social. 2003. 
PROGRAMA de las Naciones Unidas para el Desarrollo. La democracia en América Latina, hacia una democracia de ciudadanas y ciudadanos. Buenos aires: Alfaguara. 2004.

RED JUVENIL DE MEDELLÍN. Informe de derechos humanos. 2007.

RESTREPO, Luis Alberto. El potencial democrático de los movimientos sociales y de la sociedad civil en Colombia. Bogotá: Editorial Gazeta. 1994.

SIGNO Y PENSAMIENTO. Radiografías. Bogotá: Departamento de Comunicación. Facultad de Comunicación y Lenguaje. Pontificia Universidad Javeriana. 1998. Volumen XVII. N. ${ }^{\circ} 3$.

TARROW, Sidney. El Poder en Movimiento. Los movimientos sociales, la acción colectiva y la política. Madrid: Alianza Universidad. 1997. 